\title{
Standardization of 3D pipeline management--a case study of Taiwan
}

\author{
Scarlet Liu ${ }^{a^{*}}$, Tony $\mathrm{Li}^{b}$ \\ a Law School, Nankai University, Tianjin 300071, China \\ ${ }^{\mathrm{b}}$ National Kaohsiung University of Applied Sciences, Kaohsiung 80778, Taiwan \\ *Corresponding author: Scarlet Liu, PhD, ciumi09@gmail.com
}

\begin{abstract}
The 3D pipeline management regulation and technical requirements had been put forward years ago. However, because of the lack of deep and detailed pipeline information, the positions of underground pipeline cannot be managed better. Thus, it will be a significant task of future pipeline management to adopt 3D GIS to provide optimal verification and regulations, improve the accuracy of pipeline data, assist in the standard management of 3D pipeline data, and speed up the accuracy and completeness of pipeline data. This paper aims to propose systematic standards and procedures for 3D pipeline, support the existing pipeline system, and set up 3D pipeline system with standard procedures and verification mechanism via project management and 3D geographic information technology. Based on the needs of road excavation management, it hopes to establish effective pipeline safety management regulations so as to enhance complete governmental management.
\end{abstract}

Key words: 3D GIS, verification mechanism, standard procedures, project management

\section{Introduction}

Information system planning is mostly based on a single system. Its design of system functions mainly focuses on the needs of a single business. However, as system designers do not thoroughly understand such business, they fail to plan in a macro and practical manner. They provide wrong information and point out wrong direction to system demanders. The contents planned are scattered. And the system does not have good usability and expandability. Most of the personnel of the demand party do not major in information. Limited by heavy workload and tight schedule, they can only discuss and guide key points. In this way, many systems developed are independent. Users are more confused and busier. And the assistance of information system in business does not reflect ${ }^{1-2}$.

Overall planning of a system shall comprehensively consider associated businesses. After business subjectivity shall be defined clearly, the business demands and materials which are 
correlated can be interconnected and shared so as to assist in overall business. By establishing 3D public facility pipeline management standards, this paper hopes to the business issues of pipeline management and road excavation. Planning shall be based on "the quality of pipeline data" rather than simply on case management. Planning shall be comprehensively designed from the aspects of practice, regulations, implementation, and decision-making. Therefore, this study would comprehensively consider the following viewpoints on "3D road information" and offer a planning of future road management which could drive resource integration and optimization ${ }^{3}$.

(1) Practice: The workflow to correct 3D pipeline data shall be correct--verify--maintain and update--coordinate conflicts--close. Standard procedures and management system would be discussed to see how to design the controlling points in workflow and implement such points via feasible practice.

(2) Regulations: New system planning must be supported by laws and regulations. Only with the promotion of public power could we have the basis of source of law. Complete planning shall be done in advance in terms of ordinances, rules for implementation, operating methods, key points, reserved administrative order space, regulatory interdependency and inheritance so as to promote new system planning in a smooth manner and at one stroke.

(3) Implementation: The establishment and management of pipeline data is only one task of road construction. The integrity of road information also contains other important tasks like road maintenance and facility management. Hence, with respect to overall 3D planning, this study would first consider the association of other road information and preserve a complete framework in planning and query system establishment. In this way, business systems can have data support among each other and form a complete 3D road information system.

(4) Decision-making: In regard to decision-making planning, based on the needs of executives, the required resources in a system can be automatically extracted to form real-time reference and integrated project viewpoints for the decision-making of executives. 


\section{Literature Review}

\subsection{Support of space techniques}

This section discusses summary of images, collection of topics, interior manufacture efficiency and quality, completeness and expansibility of results, and construction of database, and lists the possible issues in planning as shown in Table 1.Table 1 - List of key issues in practice 1

Table 1 - List of key issues in practice1

\begin{tabular}{|c|l|l|}
\hline No. & \multicolumn{1}{|c|}{ Key Problems } & \multicolumn{1}{|c|}{ Review and Correction } \\
\hline 1 & $\begin{array}{l}\text { There are dramatic changes in the current } \\
\text { situation of pipeline and fixed facilities. }\end{array}$ & $\begin{array}{l}\text { Fieldwork measurement shall be planned in } \\
\text { advance. Especially, special facilities, like poles for } \\
\text { both road lamp and traffic indicate, shall be } \\
\text { included in planning in advance. Interpreters of } \\
\text { exterior and interior measurements shall be trained } \\
\text { via videos to avoid the constant changes in } \\
\text { investigation standards resulting in wrong } \\
\text { judgement. }\end{array}$ \\
\hline 2 & $\begin{array}{l}\text { Each pipeline unit has a different schedule to } \\
\text { provide pipeline data. Drawing check cannot } \\
\text { be conducted during fieldwork measurement, } \\
\text { leading to the delay of the overall schedule. }\end{array}$ & $\begin{array}{l}\text { A meeting shall be held for pipeline units to explain } \\
\text { the plan and agree with matters of coordination and } \\
\text { scheduling to ensure smooth connection between } \\
\text { data required and exterior and interior work. }\end{array}$ \\
\hline 3 & $\begin{array}{l}\text { The hand holes adopted by pipeline units are } \\
\text { not consistent leading to repeated } \\
\text { confirmation and low measurement speed. }\end{array}$ & $\begin{array}{l}\text { Before fieldwork measurement, unified signs and } \\
\text { codes shall be set up so that the personnel of } \\
\text { interior work can also understand the contents of } \\
\text { manhead and facility. }\end{array}$ \\
\hline 4 & $\begin{array}{l}\text { There are great differences in the measuring } \\
\text { scales and drawing methods provided by } \\
\text { pipeline units, resulting in big difficulties in } \\
\text { integration and sketch and influencing } \\
\text { outcome quality and progress. }\end{array}$ & $\begin{array}{l}\text { Standard sketch procedures from measurement data } \\
\text { capture to sketch shall be developed to guide the } \\
\text { relevant personnel to produce outcomes with } \\
\text { consistent quality }\end{array}$ \\
\hline
\end{tabular}

This study summarized the above issues for the purpose of public pipeline equipment and road survey results. It considered circulation of images and maximization of added-value. It put forward the vision of image integration planning and extended system ${ }^{4-5}$. 


\subsection{Supporting government format and improving the presentation of a large number of pipelines}

This study clearly understands that the fitness of system format is vital to the convenience of system data. Thus, with respect to the image application of system, it must be considered that if pipeline data support GML. Hence, geographic information cooperation shall be carried out to reduce format incompatibility ${ }^{6-10}$. In addition, the big data presentation technology of 3D GIS has always been a hot topic in the field of GIS. Most governmental pipeline database have over one million entries of data. 3D platform must provide overlay terrain base map based on the big data and smoothly present building model ${ }^{11-16}$. The party providing geographic information and cooperating with this study does not use model to present 3D pipeline but generate based on the existing pipeline. Leveraging on excellent LOD algorithm, and based on the measurements by Kaohsiung City, Public Works Department, and New Taipei City Government, 1.10 million entries of pipeline data had been collected. An update rate of 30 frames per second (FPS) 500 meters above the ground is maintained, which significantly increases the availability of system ${ }^{17-21}$.

Table 2 - List of practical and operational experience

\section{Successful Cases}

Public Works Bureau, Kaohsiung City—Stage 21.10 million entries of data, height: 500m, FPS: 30-31 pipeline test information

\begin{tabular}{lll|l} 
Academia & Sinica & SinicaOview & 74,744 buildings kmz
\end{tabular}

System-Buildings in Taipei

SGS Kaohsiung Branch-Love River car point Single (LSA) file 71.8GB

cloud information

SGS Kaohsiung Branch-SketchUp model

\section{Establishment of verification standards and quality of pipeline data}

The establishment of 3D public facility pipeline database shall consider feasibility rather than technical convenience. See the following key points ${ }^{22-26}$ :

(1) Project characteristics: Pipeline units shall be responsible for the update and maintenance of current data source and future data. Hence, the tools and feasibility of onsite operation of construction staffs shall be considered.

(2) Standard operating procedures: SOP shall be set up according to onsite construction operation and system shall match project life cycle so that control data can be established. 
(3) Maintenance: Pipeline units shall be responsible for the update and maintenance of current data source and future data. Hence, the tools and feasibility of onsite operation of construction staffs shall be considered.

(4) Compliance with data standards and operating regulations: Data configuration shall be consistent with the latest version of Public Facility Pipeline Data Standards (At present, the draft has been developed. And public opinions are being collected. The latest information is published on the website of standards (URL: https://standards.moi.gov.tw/). New 3D data configuration regulations shall not be set up, otherwise it will disturb pipeline units and influence the overall cooperation of update and maintenance.

(5) Verification, acceptance, and quality inspection: Data quality and consistency can be ensured by following the latest version of data standards, the newly published annual "Common Specifications for Public Facility Pipeline Database Configuration", and regulations on outcome acceptance.

(6) 3D pipeline data program conversion verification: 3D public facility pipeline database shall be converted and verified by the program side based on data standards. The program verified shall ensure simulation in 3D pipeline geographic information system.

\section{3D pipeline system and data planning}

In the application of 3D public facility pipeline, it is extremely vital to allow users to easily and fast identify position and surrounding environment. Once an accident occurs, users can quickly grasp surrounding environment. In addition, this study used tilt photography 3D reconstruction technology to produce 3D building model and orthophoto images to complete ultra-high fidelity of urban model production and provide operators with intuitive identification of position. Moreover, it enhanced user convenience. This study conducted basic image processing and conversion in the demonstrate (including, administrative map, aerial photography, urban street planning, road name, important landmark, and address). And, in accordance with the categories and items of existing 2D pipeline manhead and fixed facilities, it established corresponding standard model database to facilitate simulation.

In workflow design, besides professional and institutionalized construction design, the verification of data correctness is the most important. 3D GIS pipeline system can make up the shortcomings of 2D system which does not have visual inspection, and provide the best tools for data review and verification. With the characteristics of spatial analysis of GIS, this 
study developed standard data import (2D/3D) check module to ensure data correctness and integrity.

\section{Conclusions}

Pipeline management often overlooked draws the attention of the public after Kaohsiung underground pipeline gas explosion. Therefore, the systematic and effective establishment and appropriate application of 3D intelligent urban pipeline database is a major topic for government agencies. As the government vigorously promotes intelligent cities, the development of 3D underground pipeline will be a major indicator to assess the development and competitiveness of intelligent cities promoted by local governments.

This study has two main purposes: First, it aims to provide an effective simulation system to pipeline unit to reduce their burden and enhance system affinity. Second, it intends to establish more rigorous data quality inspection procedures to control error rate. Through the mechanism, it allows 3D pipeline system to control newly set pipeline and improve the integrity and correctness of existing ones. Space techniques can be integrated in system design and play a significant role in data check and verification. Therefore, people can understand that 3D system can be applied to more areas besides large-scale terrain and model display.

The construction of 3D underground pipeline mainly covers the presentation of pipeline data. Survey information has 3D effect. Users can use 3D underground pipeline system to check the relevant geographical location of all types of pipeline. The location and depth of underground pipeline are truthfully reflected. The situation that pipeline is destroyed during excavation due to the insufficient plane data will not occur. A variety of GIS analysis functions, such as measurement, query, spatial analysis, connectivity analysis, and burst analysis, can be used to reduce the damages caused by accidents, facilitate users to conduct more spatial analysis and visual data verification, and list and quantity conflict points for correction. In combination with technological progress and demand, a complete set of pipeline management procedures shall be developed, which can not only improve pipeline management performance, but also offer 3D pipeline management solutions for outbound marketing.

The 3D pipeline verification solution mentioned in this paper can develop spatial information of intelligent cities in various fields. This study hopes that Taiwan can adopt 3D spatial analysis technology to enhance its international status, and facilitate government departments 
at all levels to rapidly complete professional decision-making support systems for urban planning, urban and rural construction, public facility planning, soil and water conservation, disaster simulation, and police affairs, so as to enhance administrative efficiency and improve governance satisfaction.

\section{References}

1. Chou, T.Y., Huang, P.H., Cheng, Y.L. 2002. Exploration on the Conversion Format of Public Pipeline Database, Land Information System Communications, Vol. 42, Taipei.

2. Chou, T.Y., Cheng, Y.L., Lin, M.X., Chao, X. 2002. Configuration, Supervision, and Acceptance of Public Pipeline Database, Land Information System Communications, Vol. 40, Taipei.

3. MAA Group. 2002. Engineering Application and Promotion of Geographical Information System, Land Information System Communications, Vol. 41, Taipei.

4. Chen, P.Y., Lin, M.S., Sung, Y.M., Sung, H.J. 2005. Study on Pipeline Excavation Application Management System and Support Governmental Policies, 2005 Annual Meeting and Seminar of Taiwan Geographical Information Society, Taichung.

5. Land Information System, http://ngis.moi.gov.tw/

6. Tsai, S.B., Wei, Y.M., Chen, K.Y., Xu, T., et al. 2016. Evaluating Green Suppliers from Green Environmental Perspective. Environment and Planning B-Planning \& Design, 2016, 43(5), 941-959.

7. Tsai, S.B. 2016. Using Grey Models for Forecasting China's Growth Trends in Renewable Energy Consumption. Clean Technologies and Environmental Policy, 2016, 18, 563-571.

8. Guo, J.J. and Tsai, S.B. 2015. Discussing and Evaluating Green Supply Chain Suppliers: A Case Study of the Printed Circuit Board Industry in China. South African Journal of Industrial Engineering, 2015, 26(2), 56-67.

9. Tsai, S.B., Huang, C.Y., Wang, C.K., Chen, Q., et al. 2016. Using a Mixed Model to Evaluate Job Satisfaction in High-Tech Industries. Plos One, 2016, 11(5): e0154071. doi:10.1371/journal.pone.0154071

10. Lee, Y.C., Chu, W.H., Chen, Q., Tsai, S.B., et al. 2016. Integrating DEMATEL Model and Failure Mode and Effects Analysis to Determine the Priority in Solving Production Problems. Advances in Mechanical Engineering, 2016, 8(4), 1-12. 
11. Tsai, S.B., Xue, Y., Zhang, J., Chen, Q., et al. 2016. Models for Forecasting Growth Trends in Renewable Energy. Renewable \& Sustainable Energy Reviews, 2016, DOI: 10.1016/j.rser.2016.06.001.

12. Qu, Q., Chen, K.Y., Wei, Y.M., et al. 2015. Using Hybrid Model to Evaluate Performance of Innovation and Technology Professionals in Marine Logistics Industry Mathematical Problems in Engineering, 2015, Article ID 361275, 8 pages, http://dx.doi.org/10.1155/2015/361275.

13. Zhou, J. Wang, Q., Tsai, S.B., et al. 2016. How to Evaluate the Job Satisfaction of Development Personnel. IEEE Transactions on Systems Man Cybernetics-Systems, 2016, 10.1109/TSMC.2016.2519860.

14. Su, J. M., Lee, S. C., Tsai, S. B. \& Lu, T. L. 2016. A comprehensive survey of the relationship between self- efficacy and performance for the governmental auditors. SpringerPlus, 2016, 5:508. DOI 10.1186/s40064-016-2104-X.

15. Tsai, S.B., Lee, Y.C. \& Guo, J.J. 2014. Using modified grey forecasting models to forecast the growth trends of green materials. Proceedings of the Institution of Mechanical Engineers, Part B: Journal of Engineering Manufacture, 2014, 228(6): 931-940.

16. Chen, H.M., Wu, C.H., Tsai, S.B., Yu, J., et al. 2016. Exploring key factors in online shopping with a hybrid model. SpringerPlus, 2016, 5:2046. DOI 10.1186/s40064-016-3746-4.

17. Deng, X.Y., Hu, Y., Deng Y. \& Mahadevan, S. 2014. Environmental impact assessment impact assessment based on numbers. Expert Systems with Applications, 2014, 41 (2), 635-643.

18. Wang, J., Yang, J., Chen Q. \& Tsai, S.B. 2016. Collaborative Production Structure of Knowledge-sharing Behavior in Internet Communities. Mobile Information Systems, Article ID 8269474, 9 pages, http://dx.doi.org/10.1155/2016/8269474.

19. Wang, J., Yang, J., Chen Q. \& Tsai, S.B. 2016. Creating the Sustainable Conditions for Knowledge Information Sharing in Virtual Community. SpringerPlus, 5:1019, DOI 10.1186/s40064-016-2702-7.

20. Lee, Y.C., Wang, Y.C., Chien, C.H., Wu, C.H., et al. 2016. Applying Revised Gap Analysis Model in Measuring Hotel Service Quality, SpringerPlus, 5:1191, DOI 10.1186/s40064-016-2823-z. 
21. Lee, Y.C., Wang, Y.C., Lu, S.C., Hsieh, Y.F., et al. 2016. An Empirical Research on Customer Satisfaction Study: A Consideration of Different Levels of Performance. SpringerPlus, 5:1577, DOI 10.1186/s40064-016-3208-z.

22. Chin, T., Tsai, S.B., Fang, K., Zhu, W., et al. 2016. EO-Performance relationships in Reverse Internationalization by Chinese Global Startup OEMs: Social Networks and Strategic Flexibility. PLoS ONE, 11(9): e0162175, doi:10.1371/journal.pone.0162175.

23. Lee, S.C., Su, J.M., Tsai, S.B., Lu, T.L., et al. 2016. A comprehensive survey of government auditors' self- efficacy and professional Development for improving audit quality. SpringerPlus, 5:1263, DOI 10.1186/s40064-016-2903-0.

24. Chen, H.M., Wu, C.H., Tsai, S.B., Yu, J., et al. 2016. Exploring key factors in online shopping with a hybrid model. SpringerPlus, 5:2046, DOI 10.1186/s40064-016-3746-4.

25. Ge, B., Jiang, D., Gao, Y., \& Tsai, S.B. 2016. The Influence of Legitimacy on a Proactive Green Orientation and Green Performance: A Study Based on Transitional Economy Scenarios in China. Sustainability, 8, 1344, 1-20. doi:10.3390/su8121344.

26. Tsai. 2017. Using the DEMATEL model to explore the job satisfaction of research and development professionals in china's photovoltaic cell industry. Renewable \& Sustainable Energy Reviews, 2017, DOI: http://dx.doi.org/10.1016/j.rser.2017.07.014 